\title{
The apolipoprotein CIII-derived peptide, HATKTAK, and stimulation of macromolecular activators of phagocytosis from platelets (MAPPs)
}

\author{
A follow-up study
}

Authors:

Haruhiko Sakamoto, M.D., Ph.D. ${ }^{1}$

Yoichi Chiba, M.D., Ph.D. ${ }^{1}$

Machi Kawauchi $^{1}$

Toshitaka Nakagawa $^{2}$

Masaki Ueno, M.D., Ph.D. ${ }^{1}$

\begin{abstract}
Affiliations:
${ }^{1}$ Inflammation Pathology, Department of Pathology and Host Defense, Faculty of Medicine, Kagawa University, Kagawa Prefecture 7610793, Japan

${ }^{2}$ Division of Research Instrument and Equipment, Life Science Research Center, Institute of Research Promotion, Kagawa University, Kagawa Prefecture 761-0793, Japan
\end{abstract}

\section{Correspondence author:}

Haruhiko Sakamoto, M.D., Ph.D., Inflammation Pathology, Department of Pathology and Host Defense, Faculty of Medicine, Kagawa University, Kagawa Prefecture 7610793, Japan.

Telephone: +81-87-891-2115.

E-mail: profsaka@med.kagawa-u.ac.jp

Running head: Apolipoprotein CIIIderived peptide, HATKTAK

\begin{abstract}
We previously reported that activated human platelets release small and large macromolecular activators of phagocytosis from platelets (SMAPP and L-MAPP, respectively), which enhance $F c \gamma$ receptor-mediated phagocytosis by neutrophils. We subsequently investigated the production and release of S-MAPP and L-MAPP by platelets as well as the structure of MAPPs. Experiments using expired platelet concentrates revealed that precursors of MAPPs (dimer or tetramer holo-transferrin) were converted to MAPPs by HATKTAK cleaved from Apo CIII on HDL in or on platelets. Immunohistochemistry showed that a rabbit IgG antibody against HATKTAK visualized not only platelets in blood coagula and thrombi, but also the foamy macrophages and smooth muscle cells of atheroma, some endothelial cells of blood vessels, glomerular filtrate, tubular epithelial cells of kidneys, and some fibers and cell bodies of neurons. HATKTAK appears to be widely distributed in the human body and plays some roles in biological reactions other than lipid metabolism. We herein review the process of investigation and describe perspectives.
\end{abstract}

Key words: platelets, neutrophils, phagocytosis, high-density lipoprotein, apolipoprotein CIII, thrombin 


\section{Introduction/ Background}

Thrombi are lesions associated with platelet activation. Hemorrhage results in platelet activation for hemostasis. Activated platelets release a number of substances from $\alpha$-granules and dense bodies and synthesize and release prostaglandins (Gordon \& Milner 1976, Macintyre 1976, Smith \& Silver 1976). The infiltration of leukocytes such as neutrophils and macrophages has been reported around these lesions (Kalimo et al. 1992, Frosch et al. 2010, Schoen \& Mitchell 2010). Circulating platelets that form complexes with neutrophils are often detected in diseases such as unstable angina, myocardial infarction, and sepsis. These platelets are considered to affect neutrophilic functions (Gawaz et al. 1995, Kirschenbaum et al. 2002, Asaduzzaman et al. 2009, Rahman et al. 2009, Duerschmied et al. 2013, Page \& Pitchford 2013, Mauler et al. 2016).

Previous studies suggested that leukocytic functions are affected by platelets. For example, leukocytic chemotaxis is induced (Weksler \& Coupal 1973. Deuel et al. 1981); phagocytosis by neutrophils and monocytes is enhanced (Sakamoto et al. 1984, Sakamoto \& Firkin 1984); enzyme release and $\mathrm{O}_{2}{ }^{-}$generation by neutrophils are induced (Laghi et al. 1985, Wu et al. 2009); lysosomal degranulation is enhanced (Del Mascio et al. 1985); the aggregation and cytotoxicity of neutrophils are induced (Boogaerts et al. 1986); the adhesion of neutrophils to endothelial cells and nylon fibers is induced (Oryu et al. 1996); the expression of some opsonin receptors is up-regulated (Sakamoto et al. 1998, Miyabe et al. 2004); the apoptosis of neutrophils is inhibited (Andonegui et al. 1997, Garlichs et al. 2004, Hartwig et al. 2014); and neutrophil extracellular trap production is accelerated (Massberg et al. 2010, Von Bruhl et al. 2012, Brill et al. 2012, Engelmann \& Massberg 2013) by platelets or products released by them.
MAPPs are platelet-derived activators of the phagocytosis of neutrophils that act via Fcy receptors (Sakamoto \& Ooshima 1986). Studies on the characterization of MAPPs and the mechanisms of MAPP activation by the apolipoprotein CIII (Apo CIII)-derived peptide, HATKTAK (Sakamoto et al. 2012) will be reviewed herein, and the perspectives of these studies through immunohistochemistry using an antibody against HATKTAK will be described.

\section{Phagocytosis assay}

Heparinized venous blood from healthy adult volunteers was used as the source of neutrophils, platelets, and plasma. Another source of platelets and plasma was expired platelet concentrates kindly supplied by the Red Cross Blood Centers of Wakayama and Kagawa Prefectures, Japan (Sakamoto \& Yokoya 1991).

In order to separate platelets and neutrophils, peripheral blood was doubly diluted with phosphate-buffered saline (PBS), layered over two layers of mixtures of Percoll and Ficoll-Paque (Pharmacia, Uppsala, Sweden) or Mono-Poly resolving medium (ICN Biochemicals Japan, Tokyo, Japan) in a polystyrene tube, and centrifuged at $60 \times \mathrm{g}$ for $15 \mathrm{~min}$. Platelets obtained from the top layer were washed twice in PBS supplemented with $6.7 \mathrm{mM}$ ethylene diamine tetra-acetate and twice in PBS. Residual blood in the tube was centrifuged again at $180 \times \mathrm{g}$ for $30 \mathrm{~min}$ and the neutrophils obtained were washed in PBS (Sakamoto \& Firkin 1984).

In order to prepare platelet-release products, washed platelets were incubated at $37^{\circ} \mathrm{C}$ in the presence of $\mathrm{Ca}^{++}$in a glass tube followed by centrifugation at $3,000 \times \mathrm{g}$ or stimulated by $0.1 \mathrm{unit} / \mathrm{mL}$ of thrombin in the presence of $\mathrm{Ca}^{++}$at $37^{\circ} \mathrm{C}$ followed by centrifugation at $4^{\circ} \mathrm{C}$. Supernatants were used as platelet-release products. 
Separated neutrophils were attached to Terasaki microplates (Nunk, Roskilde, Denmark) $\quad(2,000 \quad$ neutrophils/well $)$, incubated with platelet-release products or other stimulants, and then with sheep red blood cells (SRBCs) sensitized with antiSRBC rabbit IgG. After the removal of SRBCs not ingested by Tris-buffered ammonium chloride solution (Boyle 1968), ingested SRBCs were counted under a light microscope.

In some experiments, a flow cytometric study using whole blood was performed to assess phagocytosis ( $\mathrm{Wu}$ et al. 2009). Briefly, $100 \mu \mathrm{L}$ of heparinized venous blood was mixed with $100 \mu \mathrm{L}$ of a stimulant prepared in RPMI 1640 supplemented with $1 \%$ bovine serum albumin, and the phagocytosis of FITClabeled E. coli (Sigma, St Luis, MO, USA) was assessed by measuring neutrophilassociated fluorescence with a flow cytometer $\quad\left(\right.$ EPICS $^{\mathbb{R}} \mathrm{XL}$, Coulter Corp., Hialeah, FL, USA).
2. Characterization and in vitro preparation of MAPPs

2.1. Effects of platelet-release products and MAPPs on neutrophilic phagocytosis

The number of SRBCs ingested by neutrophils that were treated with plateletrelease products was more than two-fold that of control neutrophils (Sakamoto \& Ooshima 1986).

The gel filtration of platelet-release products on Sephadex G200 (Pharmacia, Uppsala, Sweden) or Superdex 200 (Pharmacia or GE Healthcare UK Ltd., Buckinghamshire, UK) revealed two peaks of phagocytosis enhancement and two of suppression. The causative substances were small and large macromolecular activators of phagocytosis from platelets (S-MAPP and LMAPP), respectively, and small and large macromolecular suppressors of phagocytosis from platelets (S-MSPP and L-MSPP), respectively. The estimated molecular sizes of S-MAPP and L-MAPP were approximately 150 and $300 \mathrm{kDa}$, while those of S-MSPP and L-MSPP were approximately 60 to 100 and 400 to 500 kDa, respectively (Figure 1-1) (Sakamoto et al. 1987, Sakamoto \& Yokoya 1991, Yokoya \& Sakamoto 1992). In the present study, MAPPs were produced in several manners, as listed in Figure 1. 


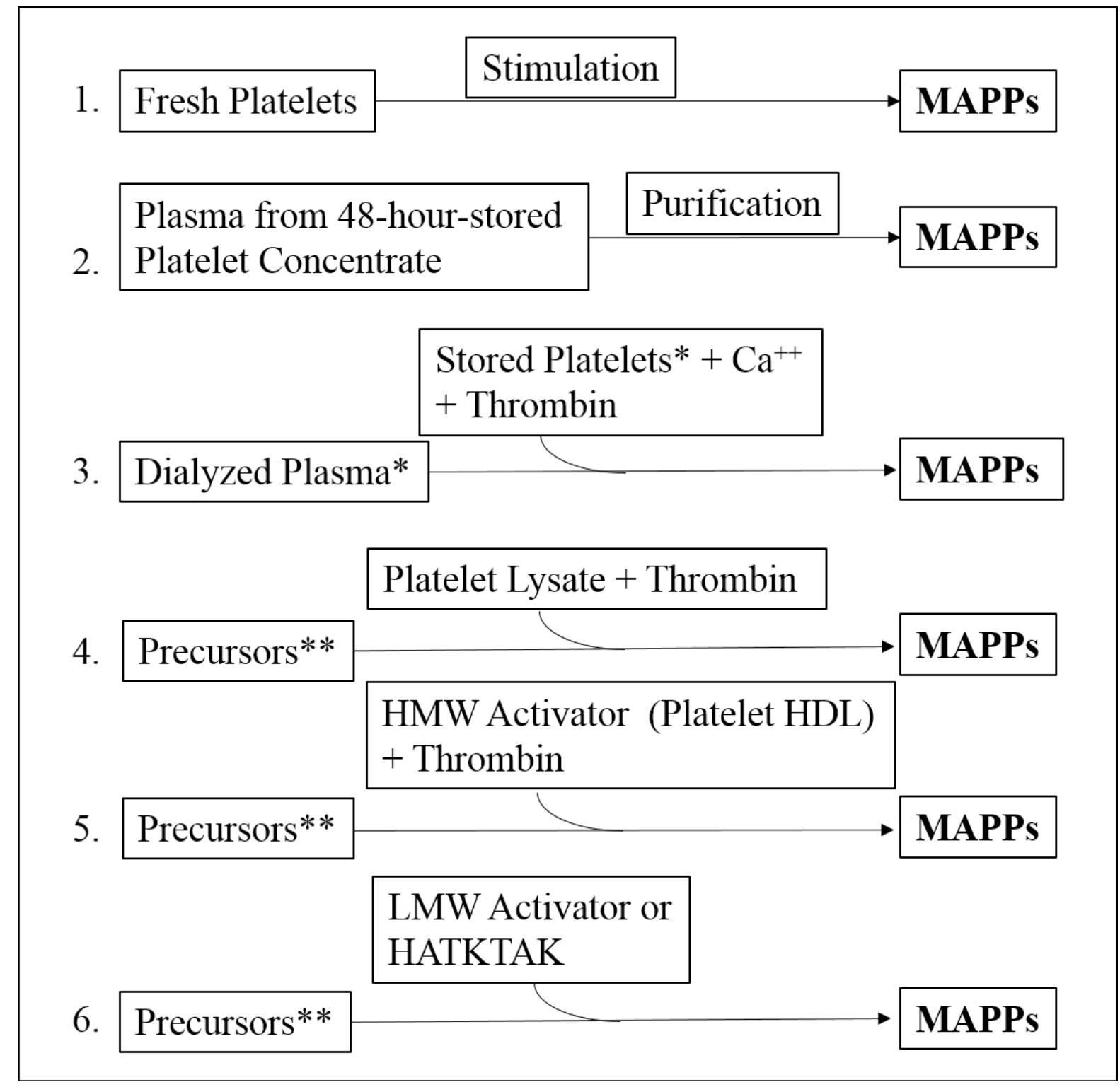

Figure 1. Methods of MAPP preparation used in this study.

*Plasma and stored platelets were obtained from platelet concentrates that were stored for more than 96 hours.

** Precursors involve plasma obtained from 96-hour-stored platelet concentrates and glutaraldehyde-treated holo-transferrin, both of which were gel-filtered on the Superdex 200 column.

In a flow cytometric analysis of phagocytosis using whole blood, plateletrelease products and MAPPs showed the activation of phagocytosis ( $\mathrm{Wu}$ et al. 2009), similar to that observed in experiments using Terasaki microplates.
2.2. Purification of MAPPs from the supernatant of stored platelet concentrates

Platelet concentrates prepared by the blood banks were initially only considered to be valid for 3 hours. Therefore, outdated 
platelets were only supplied several hours after blood was collected if they were not used for patients. We verified the phagocytosis-activating function of plateletrelease products from the platelets of expired platelet concentrates. However, the cut-off time for the storage of platelets was subsequently extended to 48 hours. We found that platelets stored for longer than 48 hours lost their MAPP-releasing function. In contrast, the supernatant of platelet concentrates maintained MAPP function (Figures 1-2) (Sakamoto \& Yokoya 1991).

By salting out with $60 \%$ saturated ammonium sulfate, we obtained MAPPs in the soluble fraction of plasma obtained from 48-hour-old platelet concentrates. We succeeded in purifying MAPPs by salting out, delipidization with ethylacetate, Con A sepharose affinity chromatography, MONO $\mathrm{Q}$ anion exchange chromatography, and gel filtration. Disc electrophoresis of purified SMAPP and L-MAPP showed single bands for both (Yokoya \& Sakamoto 1992).

Regarding MSPPs, Superdex 200 gel filtration of the precipitate of salting out with $30 \%$ saturated ammonium sulfate revealed two peaks of MSPP activity. However, this activity disappeared with further purification procedures (Yokoya \& Sakamoto 1992).

\subsection{MAPP production using stored platelets}

Although we previously succeeded in purifying MAPPs from the supernatant of platelet concentrates stored for 48 hours, the expiration time of the platelet concentrates collected was subsequently extended to 72 hours. We obtained platelet concentrates more than 96 hours after blood drawing when even the supernatant of the platelet concentrates had lost MAPP activity. We hypothesized that stored platelets that have lost their MAPP-releasing function may recover it if the anticoagulant is removed and $\mathrm{Ca}^{++}$is supplied, and investigated this

Copyright 2017 KEI Journals. All Rights Reserved possibility (Figures 1-3) (Sakamoto et al. 1996).

Platelets and plasma were prepared from platelet concentrates stored for 96 hours. Washed platelets were incubated with plasma dialyzed against PBS in the presence of $\mathrm{Ca}^{++}$and then stimulated by thrombin. We identified MAPPs in the platelet-release products of these stored platelets. Plasma was then applied to a Superdex 200 column, each fraction of which was used instead of whole plasma for MAPP production, and fractions corresponding to those of S-MAPP and L-MAPP yielded MAPP function. These findings suggested that the precursors of MAPPs are present in plasma with nearly the same molecular sizes as S-MAPP and LMAPP, and also that stored platelets maintain their function to produce MAPPs.

\subsection{Dimer and tetramer transferrins are the precursors of MAPPs}

Monoclonal antibodies against MAPPs were prepared using biochemically purified S-MAPP and L-MAPP as antigens. S-MAPP and L-MAPP purified from plasma prepared from 48-hour-old platelet concentrates by affinity chromatography using these antibodies showed MAPP functions (Yokoya et al. 1992). Peptides obtained by the digestion of affinity-purified S-MAPP with lysyl endopeptidase (Wako Pure Chemicals, Osaka, Japan) had an identical amino acid sequence to transferrin (V1-V8, K434-K455, K545-K552) (Sakamoto et al. 1997).

The facts that S-MAPP has identical amino acid sequences to transferrin and the molecular sizes of MAPPs are nearly twoand four-fold that of transferrin led us to hypothesize that the precursors of MAPPs may be dimers and tetramers of holotransferrin.

Therefore, we treated holo-transferrin (Sigma, St Louis, MO, USA) with glutaraldehyde to produce multimers of 
transferrin.

Glutaraldehyde-treated transferrin was incubated with stored platelets and thrombin in the presence of $\mathrm{Ca}^{++}$. MAPPs were observed in the supernatant of this platelet suspension. The gel filtration of this supernatant revealed a phagocytosis-activating function at the same elution volumes as S-MAPP and L-MAPP. Next, the gel-filtration of glutaraldehydetreated transferrin was performed, and MAPPs were produced by incubating stored platelets with each fraction of glutaraldehyde-treated transferrin and thrombin. MAPP function was observed in platelets incubated with the fractions corresponding to the molecular sizes of dimer and tetramer transferrins. These findings suggested that dimer and tetramer transferrins are the precursors of S- and LMAPP, respectively. Further studies were conducted in order to confirm this.

The gel filtration of glutaraldehydetreated transferrin was performed followed by native PAGE of each fraction. The findings obtained demonstrated that the multimers of transferrins in native PAGE are electrophoresed in the reverse order of their molecular sizes. By using extracted material from slices of the gel after the electrophoresis of glutaraldehyde-treated transferrin for MAPP formation, we confirmed that dimer and tetramer transferrins are the precursors of S-MAPP and L-MAPP, respectively (Sakamoto et al. 1997).

\subsection{GPIba-bound thrombin induces MAPP production}

In an attempt to clarify whether thrombin bound to the thrombin receptor is involved in MAPP production, and if so, which thrombin receptor is bound by thrombin to produce MAPPs, the following experiment was performed. MAPP formation using stored platelets was achieved by incubations with thrombin and artificially-produced precursors of MAPPs from holo-transferrin in the presence of peptides with the same amino acid sequence as the thrombin-binding site of the thrombin receptor or the monoclonal antibody against thrombin receptors. Stored platelets failed to produce MAPPs if the peptide, DYYPEEDTEGD (the amino acid sequence of the high-affinity thrombin receptor, GP1ba) or monoclonal antibody PM 6/40 (a monoclonal antibody against high-affinity thrombin receptor) was present. These findings suggested that thrombin bound to the high-affinity thrombin receptor GP Ib $\alpha$ induces MAPP production (Sakamoto et al. $\underline{2000}$ ).

\subsection{Production of MAPPs using platelet lysates}

In order to analyze MAPP production mechanisms in platelets in more detail, we attempted to produce MAPPs using platelet lysates (Figure 1-4). Platelets from stored platelet concentrates were freeze-thawed and centrifuged. When the supernatant was incubated with precursors of MAPPs and thrombin, MAPPs were obtained. When the sediment was used, MAPPs were not produced.

MAPP production was then performed in the presence of antithrombin III in order to clarify whether thrombin reacts with the platelet lysate or precursors. When the platelet lysate and thrombin were initially incubated and then antithrombin and the precursors were added, MAPP production was as high as that without antithrombin III, whereas when the precursors of MAPPs (dimer or tetramer holo-transferrin) and thrombin were initially incubated and antithrombin III and the platelet lysate were then added, MAPP production was lower (Ogawa et al. 2000). These findings suggested that thrombin reacts with platelet lysate-derived substances when MAPPs are formed. 


\subsection{Characterization of the substance in the platelet lysate contributing to MAPP production}

In order to characterize the factor in the platelet lysate responsible for MAPP production, the platelet lysate was gelfiltered and MAPPs were produced using the fractionated materials. We observed a peak in MAPP production in the macromolecular fraction. Thrombin may have digested the high-molecular-weight (HMW) activator and the cleaved substance may have functioned as an activator of MAPPs (Figures 1-5). In order to confirm this possibility, we performed another gel filtration of the thrombin-treated HMW activator on a Superdex peptide column (GE Healthcare UK Ltd.). The fraction corresponding to a molecular size of approximately $800 \mathrm{Da}$ exhibited MAPP-forming activity when incubated with the precursors of MAPPs. This substance was named the lowmolecular-weight (LMW) activator.

Since the delipidization of the HMW activator with ethylacetate at an acidic $\mathrm{pH}$ indicated that it is fat-soluble, ultracentrifugation of the platelet lysate was performed. HMW activator activity was observed in the fraction with a density of 1.063 to 1.21 (high-density lipoprotein (HDL)-rich fraction). Affinity chromatography using columns bound by antiapolipoprotein antibodies was then performed. The ability of the HDL fraction of the platelet lysate to produce MAPPs was negated by the anti-Apo A1 antibody, but not by anti-Apo B100 antibodies. These findings strongly suggested that the HMW activator belongs to HDL. The HDL fraction of the platelet lysate was separated into lipid and protein fractions by extraction using ether-alcohol. MAPP-forming function was observed in the protein fraction. Affinity chromatography of the protein fraction was performed. A MAPP-producing substance was obtained from the material adsorbed to an anti-Apo CIII column (Sakamoto et al. 2011).

\section{Structure of the LMW activator}

\subsection{Characterization of the LMW activator}

Since Apo CIII needs thrombin to produce MAPPs and the suggested molecular size of the LMW activator is 800 , purchased Apo CIII (Chemicon International Inc., Temecula, CA, USA) was treated with thrombin, and cation exchange chromatography using the MONO S column (GE Healthcare UK Ltd.) was performed. The findings obtained indicated that the LMW activator is a cationic peptide. When trypsin (Sigma) was used instead of thrombin, LMW activator function with the same characteristics was observed. Trypsin was more effective than thrombin in vitro.

These findings suggested that the LMW activator is a peptide included in the amino acid sequence of Apo CIII, a cationic peptide of approximately $800 \mathrm{Da}$. Since trypsin produces the LMW activator, the Nterminal of the LMW activator is considered to be an amino acid after $\mathrm{K}$ or $\mathrm{R}$ of Apo CIII and the $\mathrm{C}$-terminal is $\mathrm{K}$ or $\mathrm{R}$. The peptide that satisfies these requirements is HATKTAK (H18-K24) (See Figure 2) (Figures 1-6). 


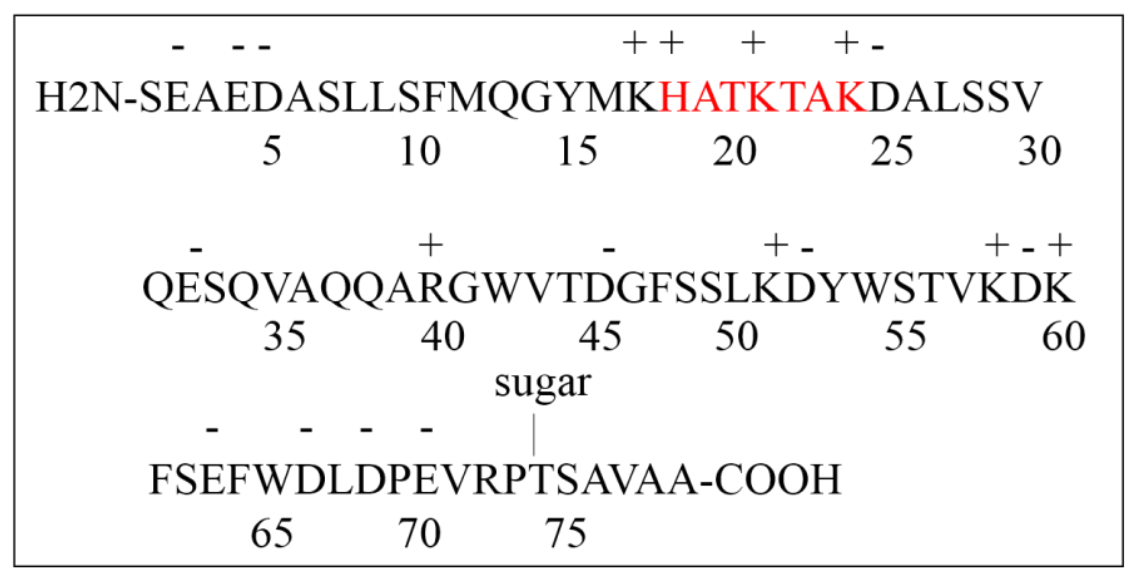

Figure 2. Amino acid sequence of apolipoprotein CIII (alphabetical designation). The LMW activator is a peptide included in the amino acid sequence of Apo CIII, a cationic peptide of approximately $800 \mathrm{Da}$. The $\mathrm{N}$-terminal amino acid is the one after $\mathrm{K}$ or $\mathrm{R}$ and the $\mathrm{C}$-terminal is $\mathrm{K}$ or $\mathrm{R}$. The corresponding peptide is HATKTAK.

A mass spectrometric study showed the existence of a substance with the same molecular size as HATKTAK, $756 \mathrm{Da}$, in trypsin-treated Apo CIII and in the plateletrelease products from 120-hour-stored platelets.

Among the peptides examined, only HATKTAK produced MAPPs (Sakamoto et al. 2012).
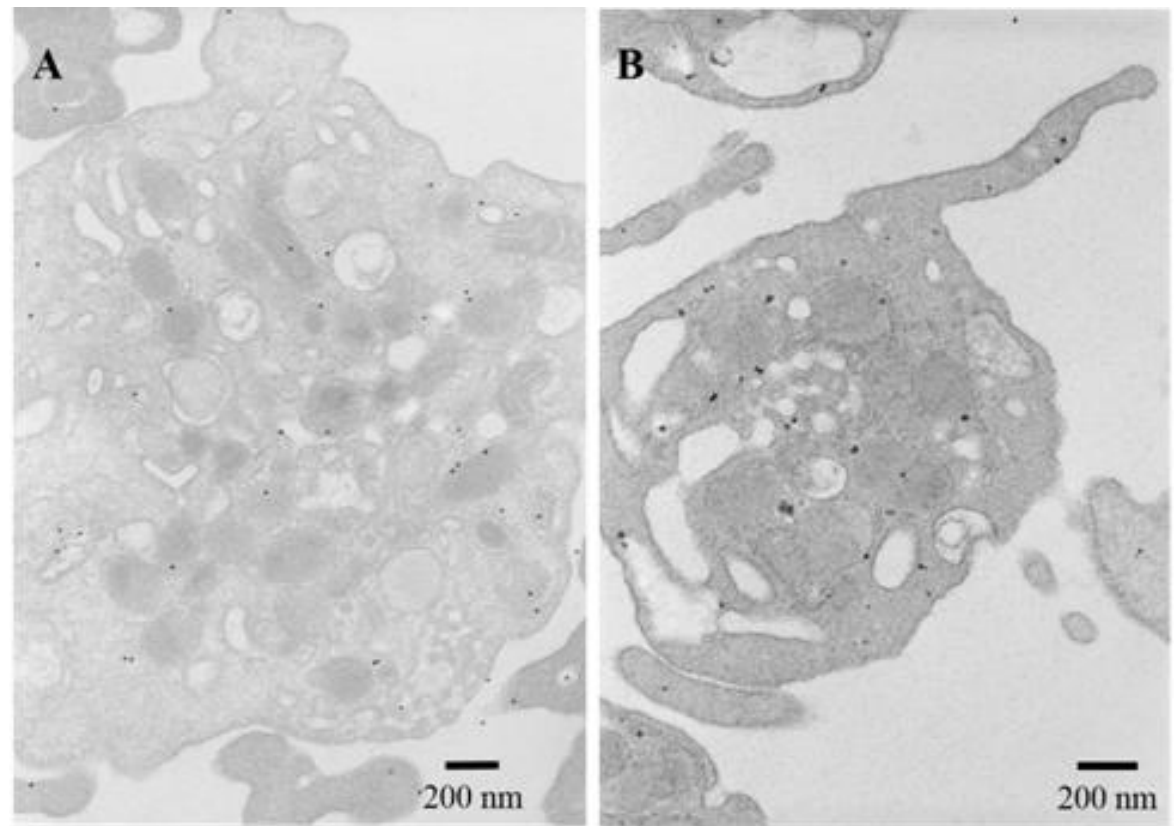

Figure 3. Immuno-electron microscopic observations of fresh (A) and stored (B) platelets using anti-Apo A1 (A) and anti-Apo CIII (B) murine monoclonal antibodies. The second antibody, the anti-mouse IgG antibody, was coupled to 10 -nm gold particles. 
3.2. Summary of the production and release of MAPPs by platelets

Figure 4 shows a diagram of MAPP production and release by platelets. The precursors of MAPPs (dimer or tetramer holo-transferrin) in plasma enter platelets in the presence of $\mathrm{Ca}^{++}$, and are converted to MAPPs by the action of HATKTAK, which is cleaved from Apo CIII on HDL. Thrombin bound to the high-affinity thrombin receptor GP Ib $\alpha$ induces MAPP production.

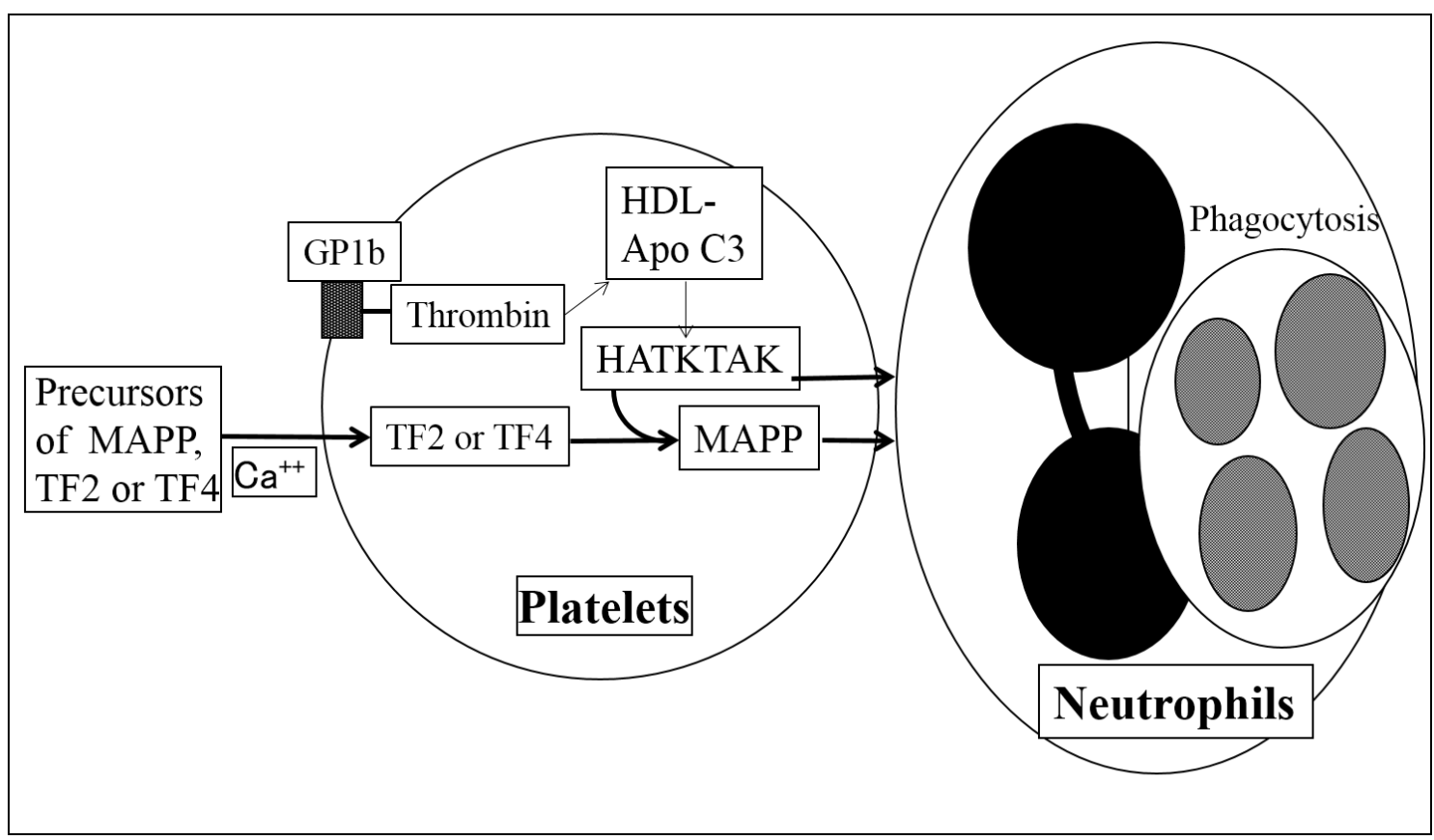

Figure 4. A diagram of MAPP production and release by platelets.

TF2, dimer transferrin; TF4, tetramer transferrin; Apo C3, apolipoprotein CIII.

\subsection{Immunohistochemistry using an anti-HATKTAK antibody}

An anti-HATKTAK antibody was prepared by the immunization of a rabbit with keyhole limpet hemocyanin-bound CHATKTAK (Sigma Aldrich Japan, Ishikari City, Japan). IgG was refined from rabbit serum on a protein A column. The antibody against keyhole limpet hemocyanin was reduced by passing IgG through a keyhole limpet hemocyanin-conjugated $\mathrm{CNBr}$ activated Sepharose column (GE Healthcare UK Ltd.).

An enzyme-linked immunosorbent assay (ELISA) revealed that this rabbit antiHATKTAK IgG reacted with HATKTAK and Apo CIII-derived peptides with HATKTAK at the C-terminal (HATKTAK- related peptides), but not with Apo CIIIderived peptides with HATKTAK at the Nterminal or whole Apo CIII.

\subsubsection{Blood coagula and thrombi}

Blood coagula obtained from human fresh peripheral blood was embedded in paraffin and 4- $\mu$ m-thick sections were prepared.

Immunohistochemistry using rabbit anti-HATKTAK IgG (x2,000 diluted, at $4^{\circ} \mathrm{C}$ overnight) showed a positive reaction on aggregated platelets. The reaction of the anti-HATKTAK antibody was the strongest 6 hours after blood drawing. The positive reaction disappeared in the presence of the antigen HATKTAK $(>10 \mu \mathrm{g} / \mathrm{mL})$. 
Confocal microscopic observations of the platelet aggregate in coagula showed that the reactions of anti-HATKTAK IgG and anti-CD61 antibody merged on platelets (Sakamoto et al. 2012).

In tissues obtained at autopsy, platelets in parts of thrombi were stained by antiHATKTAK IgG, whereas an anti-CD61 reaction was observed throughout thrombi. As shown in an experiment on blood coagula, the positive reaction of platelets became weaker when thrombi aged (Yamanaka et al. 2013).

\subsubsection{Preliminary Immunohisto-} chemical studies on atheroma, the urinary system, and nervous system

In atherosclerotic lesions of the aorta and coronary artery obtained at autopsy, a positive reaction of anti-HATKTAK $\mathrm{IgG}$ was observed on platelets in the thrombus, in the cytoplasm of foamy macrophages (Figure 5), and in the cytoplasm around the nuclei of smooth muscle cells of the media. Some endothelial cells of blood vessels were also visualized by anti-HATKTAK IgG.

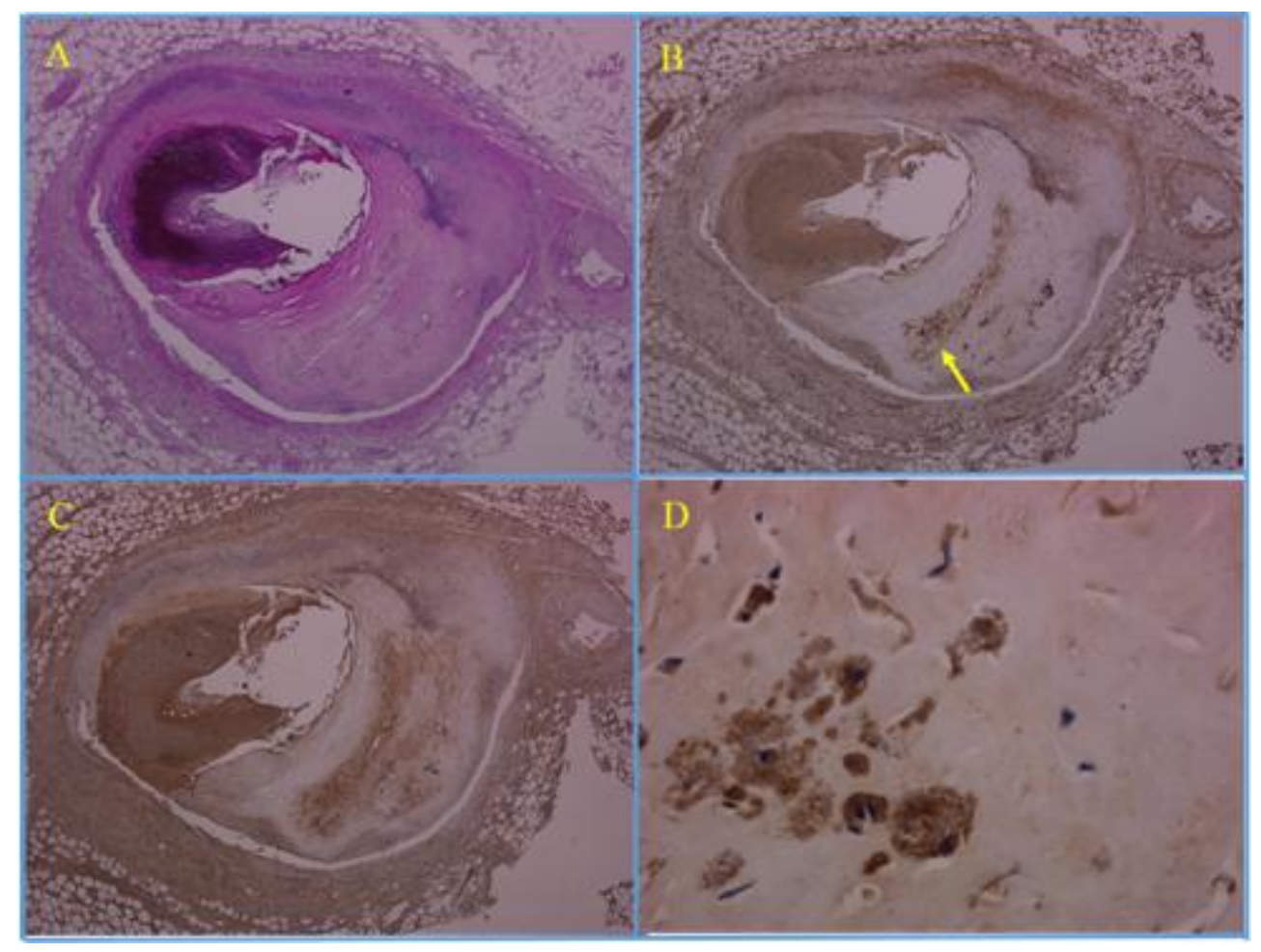

Figure 5. Immunohistochemistry of the coronary artery with atheroma and a thrombus. A, Hematoxylin-eosin stain; B, immunostaining with an anti-HATKTAK antibody; C, immunostaining with an anti-Apo CIII antibody; D, immunostaining with an anti-HATKTAK antibody. Foamy macrophages in the atheroma are indicated by the arrow in B.

In the urinary system, a strong positive reaction of anti-HATKTAK $\operatorname{IgG}$ was observed in the glomerular filtrate, a moderate to marked reaction in the epithelial cells of the proximal convoluted tubules of the kidneys (Figure 6), and a mild to moderate reaction in the epithelial cells of the ureter and urinary bladder obtained at autopsy. 


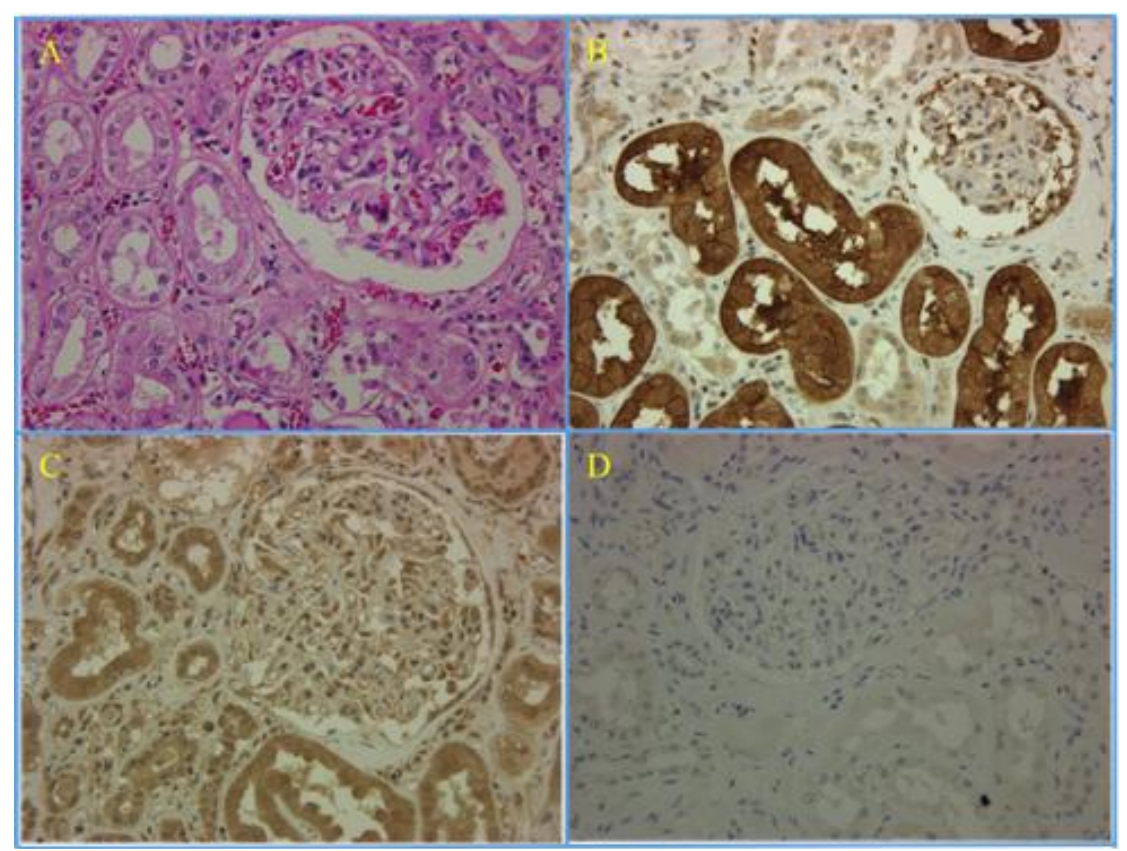

Figure 6. Immunohistochemistry of kidneys using anti-HATKTAK IgG. A, Hematoxylin eosin stain; B, immunostaining with an anti-HATKTAK IgG; C, immunostaining with an anti-Apo CIII antibody; D, immunostaining with an anti-HATKTAK antibody with blocking by the peptide, HATKTAK.

Some nerve fibers and cells were positively stained with anti-HATKTAK IgG. Positive reactions were observed in the central and peripheral nervous systems. The positive reaction for anti-HATKTAK IgG was inhibited by HATKTAK. Control IgG did not show a positive reaction (Figure 7).

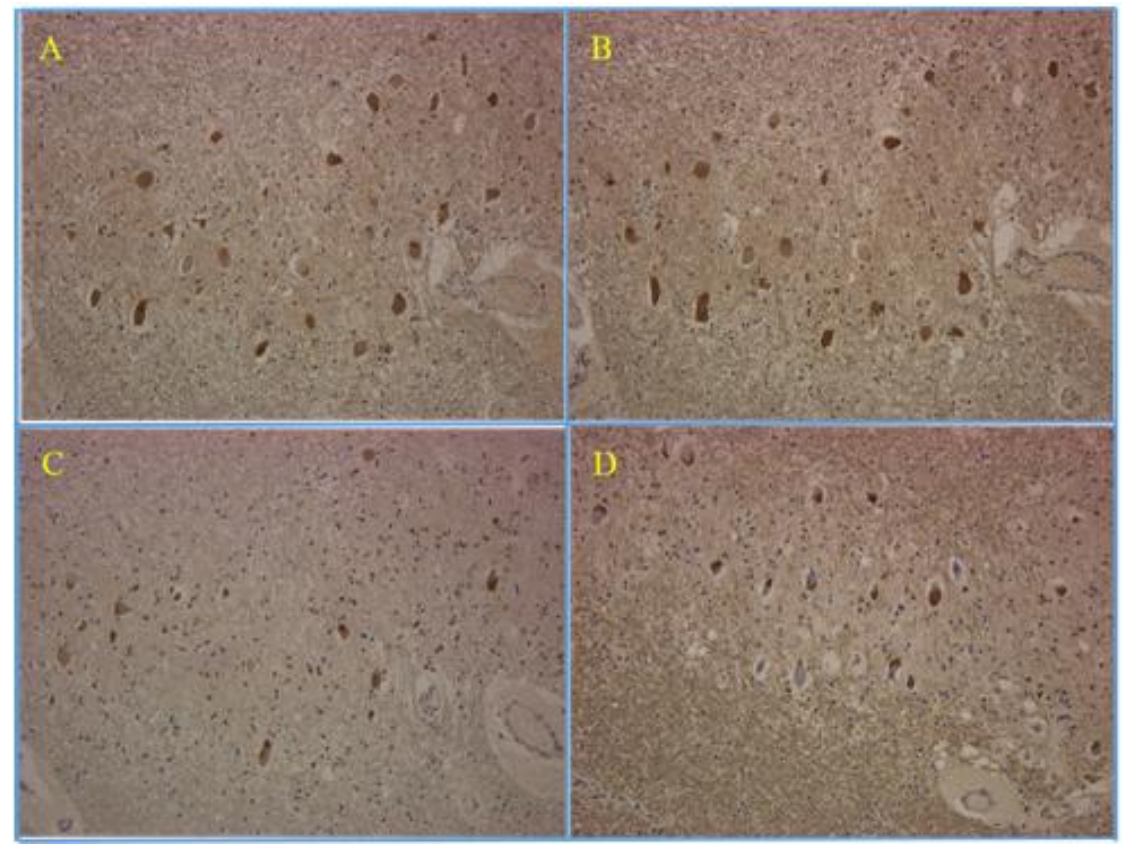

Figure 7. Immunohistochemistry of the dentate nucleus of the cerebellum using antiHATKTAK IgG. A, Anti-HATKTAK IgG + PBS; B, anti-HATKTAK IgG + keyhole limpet hemocyanin; C, anti-HATKTAK IgG + HATKTAK; D, normal rabbit (control) IgG. 


\section{Discussion/Perspectives on our study}

The duration during which platelet concentrates were considered to be viable was initially very short (3 hours); however, it was gradually extended to 72 hours and then to 96 hours from 2004. Our research using expired platelets was markedly affected by this extension. We found that activated platelets produced and released MAPPs along with the production and release of HATKTAK, which is a peptide involved in Apo CIII (H18-K24).

Apo CIII consists of 79 amino acids, is mainly synthesized in the liver and intestines (Jong et al. 1999), is a constituent of lipoproteins such as chylomicrons, very-low density lipoprotein (VLDL), and HDL, and inhibits lipoprotein lipase in vascular endothelial cells (Wang et al. 1985). It is transferred from one lipoprotein to another and is not equally distributed between these lipoproteins. In normolipidemic individuals, most ApoC-III is in HDL; however, Apo CIII comprises less than half of HDL in plasma (Fredenrich et al. 1997). In patients with triglyceridemia, more Apo CIII is in triglyceride-rich lipoproteins (Schonfeld et al. 1979).

To the best of our knowledge, the digestion of Apo CIII has not yet been examined in detail, except in some in vitro studies (Hospattankar et al. 1986). Our findings indicated that peptides cleaved from Apo CIII function in biological reactions other than lipid metabolism. The ability of thrombin to cleave HATKTAK from Apo CIII was markedly weaker than that of trypsin in vitro from the standpoint of concentration. The trypsin-like activity of thrombin may be enhanced by binding to GP Ib $\alpha$.

Our findings demonstrated that CPDstored platelets did not exhibit MAPPproducing or -releasing functions in 48 hours, but recovered them if incubated with the precursors of MAPPs and thrombin in the presence of $\mathrm{Ca}^{++}$. Therefore, CPD-stored platelets lose thrombin and the precursors of MAPPs, but retain HDL. Reductions in thrombin in CPD-stored platelets were previously reported in an immuno-electron microscopic study (Sakamoto et al. 1997).

Platelets have the HDL receptor, SRBI, which exists on the platelet cell membrane. Platelets were previously suggested to discharge cholesteryl esters via SRBI (Imachi et al. 2003). Koller et al. reported that the glycoprotein (GP) IIb-IIIa, one of the major platelet membrane constituents, binds to HDL and LDL in addition to fibrinogen (Koller et al. 1989). Platelet GP1b is a receptor for vonWillebrand factor, which connects platelets and subendothelial collagen, while GPIIbIIIa binds fibrin and connects platelets together. These are phenomena that occur outside of platelets. However, since platelet cell membranes and those of the open canalicular system are continuous, they may share many molecules with receptor functions. Previous studies reported that both areas of membranes have receptors such as GPIb (White et al. 1999) and GPIIbIIIa (Woods et al. 1986). Immunoelectron microscopic observations of platelets revealed the existence of more Apo A1, Apo CIII, and thrombin in an open canalicular system and $\alpha$-granule-like structures than on platelet cell membranes. Platelets have been shown to transport tissue factors into open canalicular systems, $\alpha$ granules, and cytoplasm (Escolar et al. 2008). Similarly, platelets may transport substances for MAPP production to these sites. MAPPs may be produced both in an open canalicular system and on the surface of platelets.

In immunohistochemistry using antiHATKTAK IgG, a positive reaction was observed in platelets with blood coagulation and in thrombi that are relatively young (Yamanaka et al. 2013). This finding suggested that HATKTAK is produced in 
activated platelets and exhausted in aggregated platelets.

Other HATKTAK-positive cells and tissues that we have observed include foamy macrophages and smooth muscle cells in atherosclerotic lesions of the aorta and coronary arteries, endothelial cells in some blood vessels, some fibers and cell bodies of neurons, and glomerular filtrates and epithelial cells of the urinary system. Although HATKTAK and HATKTAKrelated peptides are derived from Apo CIII, they may have wider roles and functions beyond those of Apo CIII. The role of HATKTAK as an activator of MAPPs is one example. Positive reactions in glomerular filtrates suggest that HATKTAK and HATKTAK-related peptides are excreted through the kidneys into urine. The positive reaction observed on the tubules of kidneys may be due to the reabsorption of HATKTAK and HATKTAK-related peptides.

Lipoproteins in degenerative and necrotic tissues and cells are considered to be ingested by macrophages and digested. The positive reaction of anti-HATKTAK antibodies in the macrophages of atheromatous lesions may reflect the digestion of Apo CIII.

The presence of a positive reaction for the anti-HATKTAK antibody in the nervous system needs to be examined more extensively in order to clarify whether HATKTAK and HATKTAK-related peptides have as yet unidentified functions in the nervous system.

We searched for HATKTAK in the National Center for Biotechnology Information database (available from http://www.ncbi.nlm.nih.gov/BLAST/) and found that only primates have HATKTAK in Apo CIII; therefore, difficulties may be associated with examining HATKTAK using typical experimental animals. The measurement of
HATKTAK in liquid test samples such as urine, plasma, serum, and bile along with immunohistochemical studies is possible and necessary for the further investigation of HATKTAK in order to clarify its biological and pathological significance. The distribution of HATKTAK and HATKTAKrelated substances in the human body including the nervous system suggests the biological importance of peptides derived from Apo CIII.

\section{Summary}

1. Human platelets release S-MAPP and L-MAPP, which enhance Fc $\gamma$ receptormediated phagocytosis by neutrophils.

2. Dimer and tetramer holotransferrins may be the precursors of S-MAPP and L-MAPP, respectively.

3. The LMW activator of MAPPs released from platelets is the peptide, HATKTAK, which is derived from Apo CIII on HDL.

4. The positive reaction of immunostaining using the anti-HATKTAK antibody was observed not only in the platelets of hemostasis and thrombi, but also in other cells and tissues. This finding suggests that HATKTAK and HATKTAK-related peptides have functions other than in lipid metabolism.

\section{Acknowledgments}

This study was approved by the Local Institutional Review Board of our University Hospital. The procedures followed were in accordance with the Helsinki Declaration of 1975.

This study was partly supported by a Grant-in-Aid for scientific research from the Ministry of Education, Japan (04807027), and by Numakuma Hospital and Kanbara Hospital, Fukuyama City, Japan, which have no conflicts of interest regarding this study. 


\section{References}

1. Andonegui G, Trevani AS, Lopez DH, Reiden S, GiordanoM and Geffner JR. Inhibition of human neutrophil apoptosis by platelets. J Immunol. 1997; 158: 3372-3377.

2. Asaduzzaman M, Lavasani S, Rahman M, Zhang S, Braum OO, Jeppsson B, et al. Platelet support pulmonary recruitment of neutrophils in abdominal sepsis. Crit Care Med. 2009; 37: 13891396.

3. Boogaerts MA, Vercelotti G, Roelant C, Malbrain S, Verwilghen RL and Jacob HS. Platelets augment granulocytes aggregation and cytotoxicity: uncovering their effects by improved cell separation techniques using Percoll gradients. Scand J Haematol. 1986; 37: 229-236.

4. Boyle W. An extension of the $51 \mathrm{Cr}$ release assay for the estimation of mouse cytotoxins. Transplantation. 1968; 6: 761-764.

5. Brill A, Fuchs TA, Savachenko AS, Thomas GM, Martinod K, De Meyer $\mathrm{SF}$, et al. Neutrophil extracellular traps promote deep vein thrombosis in mice. J Thromb Haemost. 2012; 10: 136-144.

6. Del Mascio A, Maclouf J, Corvazier E, Grange MJ and Borgreat P. Activated platelets stimulate human neutrophils functions. Nourv Rev Fr Hematol. 1985; 27: 275-278.

7. Deuel TF, Senior RM, Chang D, Griffin GL, Heinvikson RL, Kaiser ET. Platelet factor 4 is chemotactic for neutrophils and monocytes. Proc Natl Acad Sci USA. 1981; 78: 4584-4587.

8. Duerschmied D, Suidan GL, Sermwea
M, Herr N, Carbo C, Brill A, et al. Platelet serotonin promoters the recruitment of neutrophils to sites of acute inflammation in mice. Blood. 2013; 121: 1008-1015.

9. Engelmann B, Massberg S. Thrombosis as an intravascular effector of innateimmunity. Nat Rev Immunol. 2013; 13: 34-45.

10. Escolar G, Lopez-Vilchez I, Diaz-Ricart M, White JG, Galan AM. Internalization of tissue factor by platelets. Thromb Res. 2008; 122: 537541

11. Fredenrich A, Giroux LM, Tremblay M, Krimbou L, Davignon J, Cohn JS. Plasma lipoprotein distribution of apoCIII in normolipidemic and hypotriglyceridemic subjects: comparison of the apoC-III to apoE ratio in different lipoprotein fractions. J Lipid Res. 1997; 38: 1421-1432.

12. Frosch MP, Anthony DC, De Girolami U. The central system. In: Kumar V, Abbas AK, Fausto NF, Aster JC, eds. Robbins and Cotran Pathologic Basis of Disease, 8th ed. Philadelphia, PA: Saunders/Elsevier, 2010; 1279-1344.

13. Garlichs CD, Eskafi S, Cicha I, Schmaeisser A, Walzog B, Raaz D, et al. Delay of neutrophil apoptosis in acute coronary syndromes. J Leukoc Biol. 2004; 75: 828-835.

14. Gawaz M, Fateh-Moghadam S, Pilz G, Gurland HJ, Werdan K. Platelet activation and interaction with leucocytes in patients with sepsis or multiple organ failure. Eur $\mathbf{J}$ Clin Invest. 1995; 25: 843-851. 
15. Gordon JL, Milner AJ. The platelet release reaction: association with adhesion and aggregation, and comparison with secretory response in other cells. In: Gordon JL, ed. Research Monographs in Cell and Tissue Physiology, Volume 1. Platelets in Biology and Pathology. Amsterdam, the Netherland: Elsevier/North-Holland Biomedical Press, 1976; 1-22.

16. Hartwig H, Drechsler M, Lievens $D$, Kramp B, von Hundelshausen P, Lutgens E, et al. Platelet-derived PF4 reduces neutrophil apoptosis following arterial occlusion. Thromb Haemost. 2014; 75: 562-564.

17. Hospattankar AV, Brewer HB, Ronan R, Fairwell T. Amino acid sequence of human plasma apolipoprotein C-III from normolipidemic subjects. FEBS Lett. 1986; 197: 67-73.

18. Imachi H, Murao K, Cao W, Tada S, Taminato $\mathrm{T}$ and Wong NCW et al. Expression of human scavenger receptor B1 on and in human platelets. Arterioscler Thromb Vasc Biol. 2003; 23: 898-904.

19. Jong MC, Hoffer MH, Havekes LM. Role of apo $\mathrm{Cs}$ in lipoprotein metabolism. Functional differences between apo $\mathrm{C} 1$, apo $\mathrm{C} 2$ and apo $\mathrm{C} 3$. Arterioscler. Thromb. Vasc. Biol. 1999: $19 ; 472-484$.

20. Kalimo H, Kaste M, Haltia M. Vascular diseases. In: Graham DI, Lantos PL, eds. Greenfield's Neuropathology, 6th ed. London: Arnold, 1992; 315-396.

21. Kirschenbaum LA, Adler D, Astiz ME, Barua RS, Saha D, Rackow EC. Mechanisms of platelet-neutrophil interactions and effects on cell filtration in septic shock. Shock. 2002; 17: 508512.
22. Koller E, Koller F, Binder ER. Purification and identification of the lipoprotein-binding proteins from human blood platelet membrane. J Biol Chem. 1989; 264: 12412-12418.

23. Laghi Pasini F, Ceccatelli L, Pasqui AL, Arrico A and Capecchi PL. Plateletdependent granulocyte activation in vitro: effect of ticlopidine. Int $\mathrm{J}$ Tiss Reac. 1985; 7: 367-372.

24. Macintyre DE. Blood platelets as multifunctional cells. In: Gordon JL, ed. Research Monographs in Cell and Tissue Physiology, Volume 1. Platelets in Biology and Pathology. Amsterdam, the Netherland: Elsevier/North-Holland Biomedical Press, 1976; 61-85.

25. Massberg S, Grahl L, von Bruehl ML, Manukyan D, Pfeiler S, Goosmann C, et al. Reciprocal coupling of coagulations and innate immunity via neutrophil serine protease. Nat Med; 2010: 887896.

26. Mauler M, Seyfert J, Haenel D, Seeba J, Guenther J, Stallman D, et al. Plateletneutrophil complex formation-a detailed in vitro analysis of murine and human blood samples. J Leukc Biol. 2016; 99: 781-789.

27. Miyabe K, Sakamoto N, Wu YH, Mori N, Sakamoto H. Effect of platelet release products on neutrophilic phagocytosis and complement receptors. Thromb Res. 2004; 114: 29-36.

28. National Center for Biotechnology Information database (available from http://www.ncbi.nlm.nih.gov/BLAST/)

29. Ogawa Y, Sakamoto H, Oryu M, Shinnou M, Sakamoto N, Wu YH, et al. Production of macromolecular activetors of phagocytosis by lysed platelets. Thromb Res. 2000; 97: 297-306. 
30. Oryu M, Sakamoto H, Ogawa Y, Tanaka S, Sakamoto N. Effects of released products from platelets on neutrophilic adhesion to endothelial cells and nylon fibers. J Leukoc Biol. 1996; 60: 77-80.

31. Page C, Pitchford S. Neutrophil and platelet complexes and their relevance to neutrophil recruitment and activation. Int Immunopharmacol. 2013; 17: 11761184.

32. Rahman M, Zhang S, Chew M, Ersson A, JeppssonB, Thorlacius H. Plateletderived CD40L (CD154) mediates neutrophil upregulation of Mac-1 and recruitment in septic lung injury. Ann Surg. 2009; 250: 783-790.

33. Sakamoto H, Firkin F. Characterization of leukocyte phagocytic stimulatory material released by activated human platelets. Br J Haematol. 1984; 57: 4760.

34. Sakamoto H, Firkin FC, Chesterman C. Stimulation of leukocyte phagocytic activity by the platelet release reaction. Pathology. 1984; 16: 126-130.

35. Sakamoto H, Ogawa Y, Sakamoto N, Oryu M, Shinnou M, Hirao T. Recovery of macromolecular activators of phagocytosis from platelets (MAPP) producing and releasing function in stored human platelets. Intern J Hematol. 1996; 63: 143-148.

36. Sakamoto H, Ooshima A. Activation of neutrophil phagocytosis of complement coated and IgG coated sheep erythrocytes by platelet release products. Br J Haematol. 1986; 16: 173181.

37. Sakamoto H, Sakamoto N, Oryu M, Kobayashi T, Ogawa Y, Ueno M, et al. A novel function of transferrin as a constituent of macromolecular activators of phagocytosis from platelets and their precursors. Biochem Biophys Res Commun. 1997; 230: 270-274.

38. Sakamoto H, Ueno M, Bin W, Nagai Y, Matsumoto K, Yamanaka T, et al. An apolipoprotein CIII-derived peptide, Hatktak, activates macromolecular activators of phagocytosis from platelets (MAPPs). In: Frank S, Kostner G, eds. Lipoprotein-Role in Health and Disease. Croatia: Intech, 2012; 721740. Available from: http://dx.doi.org/10.5772/48173

39. Sakamoto H, Ueno M, Wu Y, Khatun R, Tanaka S, Miyabe K, et al. Glycoprotein Iba-bound thrombin functions as a serine protease to produce macromolecular activators of phagocytosis from platelets. Biochem Biophys Res Commun. 2000; 270: 377382.

40. Sakamoto H, Wu B, Nagai Y, Tanaka S, Onodera M, Ogawa T, et al. Platelet high-density lipoprotein activates transferrin-derived phagocytosis activators, MAPPs, following thrombin digestion. Platelets. 2011; 22: 371-379.

41. Sakamoto H, Yokoya Y. Purification and characterization of macromolecular phagocytosis activators released from platelets. J Leukoc Biol. 1991; 50: 356-363.

42. Sakamoto H, Yokoya Y, Ooshima A. In vitro control of neutrophilic phagocytosis of IgG coated SRBC by macromolecules involved in released products from platelets. J Leukoc Biol. 1987; 41: 55-62.

43. Sakamoto N, Sakamoto H, Tanaka S, Oryu M, Ogawa Y. Effects of platelet release products on neutrophilic $\mathrm{Fc} \gamma$ receptors. J Leukoc Biol. 1998; 64: 


\section{1-635.}

44. Schoen FJ, Mitchell RN. The heart. In: Kumar V, Abbas AK, Fausto NF, Aster JC, eds. Robbins and Cotran Pathologic Basis of Disease, 8th ed. Philadelphia, PA: Saunders/Elsevier, 2010; 529-587.

45. Schonfeld G, George PK, Miller J, Reilly $\mathrm{P}$ and Witzum J. Apolipoprotein C-II and C-III levels in hyperlipoproteinemia. Metabolism. 1979; 28: 1001-1010.

46. Smith JB, Silver MJ. Prostaglandin synthesis by platelets and its biological significance. In: Gordon JL, ed. Research Monographs in Cell and Tissue Physiology, Volume 1. Platelets in Biology and Pathology. Amsterdam, the Netherland: Elsevier/North Holland Biomedical Press, 1976; 331-352.

47. Von Bruhl ML, Strak K, Steinhart S, Chandraratne S, Konrad L, Lorenz M, et al. Monocytes neutrophils, and platelets cooperate to initiate and propagate venous thrombosis in mice in vivo. $\mathbf{J}$ Exp Med. 2012; 209: 819-835.

48. Wang CS, McConathy, Kloer HU, Alaupovic P. Modulation of lipoprotein lipase activity by apolipoproteins. J Clin Invest. 1985; 75: 384-390.

49. Weksler BB and Coupal CE. Plateletdependent generation of chemotactic activity in serum. J Exp Med. 1973; 137: 1419-1430.
50. White JG, Krumwiede MD and Escolar G. Glycoprotein Ib is homogeneously distributed on external and internal membranes of resting platelets. Am J Pathol. 1999; 155: 2127-2134.

51. Woods Jr VL, Wolf LE, Keller DM. Resting platelets contain a substantial centrally located pool of glycoprotein IIb-IIIa complex which may be accessible to some but not other extracellular proteins. J Biol Chem. 1986; 261; 15242-15251.

52. Wu B, Liu G, Yube K, Ueno M, Tanaka $\mathrm{S}$, Onodera M, et al. Effects of platelet release products on neutrophilic activity in human whole blood. Inflamm Res. 2009; 58: 321-328.

53. Yamanaka T, Sakamoto $H$, Nakagawa $\mathrm{T}$, Tanaka $\mathrm{S}$, Matsumoto $\mathrm{K}$ and Ueno M. An immunohistochemical study of human platelets using a rabbit antibody against H18-K24 of apolipoprotein CIII (HATKTAK). Pathology International. 2013; 63: 398-407.

54. Yokoya Y and Sakamoto H. Escape of phagocytosis-activating function from platelets into plasma during storage. Vox Sang. 1992; 62: 34-38.

55. Yokoya Y, Sakamoto H, Oryu M, Uda H. Studies on macromolecular activators of phagocytosis from platelets (MAPPs) using anti MAPP murine monoclonal antibodies. Br J Haematol. 1992; 81: 241-246. 